\title{
TTR
}

Traduction, terminologie, re?daction

\section{Livius. Revista de estudios de traducción, nos 13/14, León, Universidad de León (España), 1999.}

\section{Alicia Urteaga}

Volume 13, numéro 2, 2e semestre 2000

Les Antilles en traduction

The Caribbean in Translation

URI : https://id.erudit.org/iderudit/037420ar

DOI : https://doi.org/10.7202/037420ar

Aller au sommaire du numéro

\section{Éditeur(s)}

Association canadienne de traductologie

ISSN

0835-8443 (imprimé)

1708-2188 (numérique)

Découvrir la revue

Citer ce compte rendu

Urteaga, A. (2000). Compte rendu de [Livius. Revista de estudios de traducción, nos 13/14, León, Universidad de León (España), 1999.] TTR, 13(2), 253-254.

https://doi.org/10.7202/037420ar

Tous droits réservés (C) TTR: traduction, terminologie, rédaction — Les auteurs, 2000

Ce document est protégé par la loi sur le droit d'auteur. L'utilisation des services d'Érudit (y compris la reproduction) est assujettie à sa politique d'utilisation que vous pouvez consulter en ligne.

https://apropos.erudit.org/fr/usagers/politique-dutilisation/ 


\section{Livius. Revista de estudios de traducción, nos 13/14, León, Universidad de León (España), 1999.}

La lectura de los números 13 y 14 de Livius. Revista de estudios de traducción (1999), publicación del Servicio de Traducción Científica y Técnica de la Escuela Universitaria de Relaciones Laborales, de la Universidad de León (España), revela características interesantes en cuanto a la calidad de las colaboraciones, la cantidad de artículos presentados y la variedad de los temas ofrecidos.

Para ejemplificar la afirmacíon precedente, señalemos que la décima tercera entrega de Livius contiene trece artículos, dos de ellos redactados en inglés: ("Translating 'Translations' : The Importance of Conversational Análisis in this Play", de Ma. Dolores Gómez Penas y Anne MacCarthy y, con la firma de Francisco Martín Miguel, "On the interplay between systemic linguistics and cultural translation"). En este número se examinan, además, aspectos de la traducción de un texto latino al castellano medieval, de los subtítulos cinematográficos y del idioma japonés al español. Predominan, sin embargo, los temas que enfocan las versiones contemporáneas de textos literarios de lengua inglesa o que analizan aspectos de la teoría traductológica.

De los quince artículos publicados en el número 14 , la mayoría analiza la traducción al español (p. ej., de textos médicos franceses, versiones de poemas de Pushkin, el contenido proverbial en una obra de Shakespeare y ciertos aspectos de la traducción cultural en las ciencias antropológicas), aunque también incluye una crítica de la 
versión inglesa de la novela La colmena y una investigacion de las traducciones al inglés, francés y alemán de la novela decimonónica española por entregas, entre otros temas.

Es de muy buena calidad el nivel de las colaboraciones, que contribuyen a esclarecer - en general desde una perspectiva novedosa - aspectos específicos o investigativos de la teoría y las técnicas de la traduccíon, sin olvidar por ello las versiones de textos pragmáticos. En efecto, a la colaboración sobre el lenguaje médico ya mencionada se agregan los artículos titulados "El traductor técnico : $\mathrm{La}$ complementariedad de la formación técnica y la Lingüística", "Más allá de la traducción : la validación de cuestionarios científico-técnicos inglés-español" y "¿QQuién teme al lobo feroz?': La telefonía móvil digital GSM y su traducción del inglés al español".

El Consejo de Redacción de Livius cuenta entre sus miembros con especialistas de trayectoria y logros reconocidos a través de las actividades pedagógica, teórica y de investigación, como es el caso de Rosa Rabadán, Gerd Wotjak y Reiner Arntz, para citar sólo algunos nombres.

De las características mencionadas puede deducirse que la revista Livius codifica una recepción culta, dirigiendo sus propuestas a un lector que se desplaza con facilidad tanto en el campo profesional y de la enseñanza superior, como también en la esfera de los estudios de traducción. Es en consecuencia una útil herramienta de actualización y de enseñanza-aprendizaje para traductores profesionales y para profesores y alumnos de los estudios de traducción. Su lectura resultará, además, interesante y esclarecedora para los amantes de la literatura ya que de ella se desprende el dinamismo y la creatividad inherentes a la labor de la traducción, lo que contribuye a erosionar la injustificada aunque persistente noción de la "invisibilidad" de quien traduce.

La revista cuenta con una diagramación sobria, de relativa atracción y de fácil lectura. Pensamos sin embargo que hubiera sido más cómodo si el índice de las colaboraciones precediera al contenido, aunque ello implique una ruptura con la tradición hispánica.

\section{Alicia Urteaga Glendon College}

